\title{
A meta-stochastic frontier analysis for energy efficiency of regions in Japan
}

\author{
Satoshi Honma ${ }^{1 *}(\mathbb{D}$ and Jin-Li Hu
}

\author{
${ }^{*}$ Correspondence: \\ honmasatoshi@tokai.ac.jp \\ ${ }^{1}$ School of Political Science \\ and Economics, Tokai \\ University, 4-1-1 Kitakaname, \\ Hiratsuka City, Kanagawa \\ 259-1292, Japan \\ Full list of author information \\ is available at the end of the \\ article
}

\begin{abstract}
This paper measures the metafrontier total-factor energy efficiency (TFEE) of 47 regions in Japan for the period 1996-2008, using the stochastic frontier analysis (SFA). The twostep output-oriented SFA approach by Huang et al. (J Prod Anal 42:241-254, 2014) is followed but converted into a two-step input-oriented SFA approach. The metafrontier TFEE is defined as a product of the group TFEE and the technological gap ratio (TGR). The mean group TFEE is smaller than the mean TGR for both the groups, which shows that the energy inefficiency in Japanese regions with respect to the metafrontier comes from primarily operating inefficiency, rather technology gap. The mean metafrontier TFEE of the metropolitan areas is smaller than that of rural areas, implying that the former is energy inefficient than the latter. The mean TGR of the metropolitan areas is also smaller than that of rural areas, implying that many Japanese regions with major cities are far below the metafrontier and still have much room for energy savings.
\end{abstract}

Keywords: Two-step input stochastic frontier analysis, Input metafrontier analysis, Energy efficiency

\section{Background}

After the Fukushima Daiichi nuclear disaster on March 11, 2011, energy conservation has been an urgent issue in Japan. After the accident, all 54 nuclear reactors in Japan had been shut down. Nowadays, due to newly introduced more stringent regulation and prospect from the public, only three nuclear plants are at work on March, 2016. Although a new feed-in tariff to promote renewable energy was introduced in July 2012, it cannot fully make up for the shortfall resulting from the cessation of nuclear power generation. Improving energy efficiency is a feasible solution to the current energy issues in Japan. To this end, we need detailed information what factors affect energy inefficiency.

Technological modernization is one of the key factors for success in improving productivity and environmental management (Yang et al. 2017). In general, a decision-making unit (DMU) can use not all available technology, but only specific technology given the current physical, social, and human capitals. Policy-makers should distinguish two inefficiencies: One is attributed to operating failures under the existing technology and the other is attributed to an inability to access the best available technology. The former can be resolved by the DMU's effort given the circumstance, but the latter cannot be mitigated without investment to state-of-the-art equipment and management system.

C) The Author(s) 2018. This article is distributed under the terms of the Creative Commons Attribution 4.0 International License (http://creativecommons.org/licenses/by/4.0/), which permits unrestricted use, distribution, and reproduction in any medium, provided you give appropriate credit to the original author(s) and the source, provide a link to the Creative Commons license, and indicate if changes were made. 
The metafrontier analysis that was advocated by Hayami and Ruttan $(1970,1971)$ and that was applied to the SFA by Battese and Rao (2002), Battese et al. (2004), and O'Donnell et al. (2008) allows us to decompose sources of inefficiency into operational inefficiency and uncontrollable production environment. The former is derived from the group technical efficiency that is measured by a distance from an actual point to the group frontier for the same technology DMUs. The latter is derived from the technology gap ratio (TGR) that is measured by a distance from the group frontier to the metafrontier. The metafrontier technical efficiency is defined as a product of the two efficiencies. Huang et al. (2014) proposed a new two-step approach that estimates both of the two efficiencies by the SFA. It overcomes a drawback of the mixed approach by Battese et al. (2004) and O'Donnell et al. (2008), in which the group efficiency is measured by the SFA in the first step and the TGR is measured by linear programming problem.

In this paper, to decompose the sources of energy efficiency in Japanese regions, we apply the metafrontier framework to the total-factor energy efficiency (TFEE) as an input efficiency with respect to energy. The TFEE is measured taken into account of other inputs such as labor and capital stock. It is advocated by $\mathrm{Hu}$ and Wang (2006) using data envelopment analysis (DEA) and is applied to the Asia-Pacific economy (Hu and Kao 2007), Japan (Honma and Hu 2008, 2013, 2014a, b), Taiwan (Hu et al. 2012), and OECD (Honma and $\mathrm{Hu} 2014 \mathrm{~b}$ ). Although the TFEE is originally defined and is measured by the DEA in the above studies, Honma and $\mathrm{Hu}$ (2014a) and $\mathrm{Hu}$ and Honma (2014) resort to the stochastic frontier analysis (SFA). This is because SFA has advantages that it can consider statistical noises and outliers compared with the DEA.

Honma and $\mathrm{Hu}$ (2014a) is a companion paper of this study, which extends the crosssectional SFA model proposed by Zhou et al. (2012) to panel data models and incorporates the technical inefficiency model proposed by Battese and Coelli (1995) into them. Fujii et al. (2016) also applies the SFA to estimate the technical and environmental efficiency scores of Japanese manufacturing industry. They find that the financial crisis worsens off the technical efficiency but not the environmental efficiency of the Japanese manufacturers.

However, there is still a lack in the literature about the metafrontier analysis of energy efficiency by using the SFA approach. The above literature could only do the overall technical, environmental, or energy efficiency estimation by SFA, without the metafrontier analysis to take into account heterogeneous subgroup technologies. A potential problem is that the estimated TGR scores may not be between zero and one if the SFA approach is applied to estimate the meta- and subgroup energy efficiency scores.

The purpose of this paper is to measure the TFEE as input efficiency using the SFA metafrontier framework and to apply it to Japanese regions. In order to take into account of technology difference of multiple groups, in this paper, we incorporate the metafrontier technique into the model of Honma and $\mathrm{Hu}$ (2014a). In contrast to Huang et al. (2014) that take the output-oriented technical efficiencies, we adopt the TFEE as an input-oriented efficiency measure to shed light on energy use. For this purpose, we classified Japanese 47 prefectures into two groups whether a region has at least a designated city, which has many functions normally performed by a prefectural government. The group TFEE for a DMU is measured among DMUs using the same technology to that DMU. The TGR is measured among all DMUs using the ideal energy consumption 
which is the real energy consumption multiplied by the group frontier TFEE of that DMU. While the former estimates the within-group technical efficiencies, the latter captures the technology gap on the basis of a distance between the metafrontier and the group frontier. The metafrontier TFEE is defined as a product of the group TFEE and the TGR.

Unlike the previous studies that evaluate energy efficiency on the basis of a common frontier, the group TFEE and the TGR allow us to identify whether the primary source of inefficiency is operation or production environment, and provide different policy implications for policy-makers depending on their values. Lower group TFEE means that operational inefficiency given the technology should be improved, while lower TGR means that the existing technology should be replaced state-of-the-art one. This extension allows us to simultaneously estimate inefficiency and its determinants. To investigate determinants of inefficiency, four industrial shares (manufacturing share, wholesale and retail trade share, and service activities share) and three economic and social conditions (share of government services, population density and income per capita) are used as environmental variables ( $z$-variables) in the group TFEE estimation. The metafrontier analysis results identify whether the primary cause for inefficiency is operation or production environment.

Ministry of the environment in Japan has been promoted prefecture governments to address greenhouse gas reduction since around 2000. In 2016, 30 prefectures introduced the greenhouse gas emissions reduction plan system that obliges large emission firms to submit the reduction plan and emission report each year. Since regional emission reduction policy is mainly introduced by prefectural governments, it would be important to measure energy efficiency in prefecture level. Measuring reginal efficiency provides useful information that a local government should focus on whether to improve operating inefficiency with the existent technology or to fulfill the technology gap between the actual state and the state of the art.

The structure of the rest of this paper is as follows. Section 2 describes our metafrontier efficiency methodology and data. Section 3 presents empirical results, and the last section provides the concluding remarks.

\section{Methods}

\subsection{Methodology}

Zhou et al. (2012) applied the single-equation, output-oriented SFA model to estimate the TFEE. Their cross-sectional SFA model was used to analyze 21 OECD countries in 2001. Combining the studies of Zhou et al. (2012) and Battese and Coelli (1992), this study expands the panel data SFA model further by estimating the TFEE.

We assume that the stochastic frontier distance function is included in the translog function as ${ }^{1}$

\footnotetext{
${ }^{1}$ In recent stochastic studies (e.g., Kumar et al. 2015; Tamaki et al. 2018), quadratic function is also used as well as translog function to estimate production function. However, because quadratic functional form input SFA failed to converge on the data, we follow translog functional form as a conventional method.
} 


$$
\begin{aligned}
\ln D_{E}\left(K_{i t}, L_{i t}, E_{i t}, Y_{i t}\right)= & b_{0}+b_{L} \ln L_{i t}+b_{K} \ln K_{i t}+b_{E} \ln E_{i t}+b_{Y} \ln Y_{i t} \\
& +\frac{1}{2} \beta_{L L} \ln L_{i t}^{2}+\frac{1}{2} \beta_{K K} \ln K_{i t}^{2}+\frac{1}{2} \beta_{Y Y} \ln Y_{i t}^{2} \\
& +\beta_{L K} \ln L_{i t} \ln K_{i t}+\beta_{L Y} \ln L_{i t} \ln Y_{i t}+\beta_{K Y} \ln K_{i t} \ln Y_{i t} \\
& +\beta_{L E} \ln L_{i t} \ln E_{i t}+\beta_{K E} \ln K_{i t} \ln E_{i t}+\beta_{Y E} \ln Y_{i t} \ln E_{i t}+v_{i t},
\end{aligned}
$$

where $D_{E}(\cdot)$ is the distance function, $L_{i t}$ is labor employment, $K_{i t}$ is the amount of capital stock, $E_{i t}$ is the energy input, $Y_{i t}$ is the real economic output, $i$ indicates the region, $t$ indicates the time, and $v_{i t}$ is the statistical noise, which is assumed to be normally distributed. ${ }^{2}$ Because the distance function is homogeneous to one degree in the energy input, the above equation can be rearranged as

$$
\ln D_{E}\left(K_{i t}, L_{i t}, E_{i t}, Y_{i t}\right)=\ln E_{i t}+\ln D_{E}\left(K_{i t}, L_{i t}, 1, Y_{i t}\right) .
$$

Substituting (1) into (2), we obtain

$$
\beta_{L E} \ln L_{i t}+\beta_{K E} \ln K_{i t}+\beta_{Y E} \ln Y_{i t}=1-\beta_{E},
$$

and then, substituting (3) into (1) and rearranging, we obtain

$$
\begin{aligned}
-\ln E_{i t}= & \beta_{0}+\beta_{L} \ln L_{i t}+\beta_{K} \ln K_{i t}+\beta_{E} \ln 1+\beta_{Y} \ln Y_{i t}+\frac{1}{2} \beta_{L L} \ln L_{i t}^{2}+\frac{1}{2} \beta_{K K} \ln K_{i t}^{2}+\frac{1}{2} \beta_{Y Y} \ln Y_{i t}^{2} \\
& +\beta_{L K} \ln L_{i t} \ln K_{i t}+\beta_{L Y} \ln L_{i t} \ln Y_{i t}+\beta_{K Y} \ln K_{i t} \ln Y_{i t}+v_{i t}-\ln D_{E}\left(K_{i t}, L_{i t}, E_{i t}, Y_{i t}\right) .
\end{aligned}
$$

Thus,

$$
\begin{aligned}
\ln \left(1 / E_{i t}\right)= & \beta_{0}+b_{L} \ln L_{i t}+\beta_{K} \ln K_{i t}+\beta_{Y} \ln Y_{i t}+\frac{1}{2} \beta_{L L} \ln L_{i t}^{2}+\frac{1}{2} \beta_{K K} \ln K_{i t}^{2}+\frac{1}{2} \beta_{Y Y} \ln Y_{i t}^{2} \\
& +\beta_{L K} \ln L_{i t} \ln K_{i t}+\beta_{L Y} \ln L_{i t} \ln Y_{i t}+\beta_{K Y} \ln K_{i t} \ln Y_{i t}+v_{i t}-u_{i t}
\end{aligned}
$$

where $u_{i t}$ is the inefficiency term, which follows a nonnegative distribution, and $v_{i t}-u_{i t}$ is the error component term of a stochastic production frontier. Equation (5) is consistent with the panel data stochastic frontier model proposed by Battese and Coelli (1992). We can examine determinants of inefficiency by Battese and Coelli (1995):

$$
u_{i t}=\delta_{0}+\delta_{1} z_{i t}^{1}+\cdots+\delta_{\mathrm{H}} z_{i t}^{H}+\varepsilon_{i t}
$$

where the $z^{1}, \ldots, z^{H}$ are environmental variables that affect the inefficiency and $\varepsilon_{i t}$ is defined by truncation of the normal distribution with mean zero and unknown variance. We take energy-intensive manufacturing industry share, non-energy-intensive manufacturing industry share, wholesale and retail trade industry share, service activities industry share, government services share, population density, income per capita, and time as the environmental variables. ${ }^{3}$ We hypothesize that rising energy-intensive manufacture industry share might lead to inefficiency due to inevitable energy consumption and that rising population density and income per capita might reduce inefficiency due to more stringent environmental regulation. Time captures the productivity changes over

\footnotetext{
${ }^{2}$ Zhou et al. (2012) assume a Cobb-Douglas function and the translog form is only referred in the appendix. For flexible estimation, we use not the Cobb-Douglas function but the translog function in Eq. (1).

${ }^{3}$ We appreciate the referee's suggestion that manufacturing industry share should be divided into energy-intensive and non-energy-intensive manufacturing shares.
} 
the sample period. The free software Frontier version 4.1, which was kindly provided by Professor Coelli (1996), can be used to estimate Eqs. (5) and (6). The TFEE of region $i$ at time $t$ is then

$$
\operatorname{TFEE}_{i t}=E\left[\exp \left(-u_{i t}\right)\right] .
$$

Therefore, we can apply the panel data stochastic production frontier approach to estimate the TFEE. Moreover, if we use disaggregated energy inputs, we can change the logged inverse energy inputs on the left-hand side of Eq. (5) and keep the other logged inputs on the right-hand side fixed, thereby obtaining the TFEE scores for different energy inputs.

Battese et al. (2004) proposed a two-stage approach to do the metafrontier analysis of the aggregate efficiency of a DMU. In the first stage, the output distance function SFA is used to estimate the group technical efficiency $\left(\mathrm{TE}_{i t}\right)$, while in the second stage the mathematical programming approach is used to compute the metafrontier technical efficiency $\left(\mathrm{TE}_{i t}^{*}\right)$. They defined the technology gap ratio (TGR) to measure the distance of a group frontier and metafrontier. They also derived the famous decomposition equation:

$$
\mathrm{TE}_{i t}^{*}=\mathrm{TE}_{i t} \times \mathrm{TGR}_{i t}
$$

where $\mathrm{TE}_{i t}^{*}$ is the metafrontier efficiency of DMU $i$ at time $t \mathrm{TE}_{i t}$ is the group efficiency of DMU $i$ at time $t$; and $\mathrm{TGR}_{i t}$ is the technology gap ratio of DMU $i$ at time $t$. Note that the more the TGR, the less the technology gap. All of the $\mathrm{TE}_{i t}^{*}, \mathrm{TE}_{i t}$, and $\mathrm{TGR}_{i t}$ are left censored at zero and right censored at 1, fitting the usual definition of an efficiency score. If in the two stages the DEA is used, the TGR scores can be used obtained by using the relation $\mathrm{TGR}_{i t}=\mathrm{TE}_{i t}^{*} / \mathrm{TE}_{i t}$. However, since the error component term in an SFA model, $v_{i t}-u_{i t}$, contains the statistical noise $v_{i t}$ which will affect the position of a stochastic frontier, in the second stage the metafrontier obtained by SFA may not be able to envelop the subgroup frontiers obtained by SFA, hence resulting in unreasonable results such as $\mathrm{TGR}_{i t}=\mathrm{TE}_{i t}^{*} / \mathrm{TE}_{i t}>1$. Therefore, Battese et al. (2004) instead used DEA in the second stage.

However, the two-stage approach of Battese et al. (2004) has inconsistent assumptions about the metafrontier and group frontiers. The metafrontier is deterministic, while the group frontiers are stochastic. In order to solve this problem, Huang et al. (2014) then proposed a new two-stage approach to correct that in Battese et al. (2004), in order to use the SFA approach in both two stages. Huang et al. (2014) suggest that in the second stage the $\mathrm{TGR}_{i t}$ score should be estimated, instead of the metafrontier efficiency score $\mathrm{TE}_{i t}^{*}$. The metafrontier efficiency score $\mathrm{TE}_{i t}^{*}$ can be obtained by multiplying $\mathrm{TE}_{i t}$ and $\mathrm{TGR}_{i t}$. Consequently, all of the $\mathrm{TE}_{i t}^{*}, \mathrm{TE}_{i t}$, and $\mathrm{TGR}_{i t}$ are left censored at 0 and right censored at 1 , fitting the usual definition of an efficiency score.

Battese et al. (2004) and Huang et al. (2014) both use the output distance function since they estimate the output technical effciency. The group maximum output level for DMU $i$ at time $t$ is $Y_{i t}^{\text {adj }}=Y_{i t} / \mathrm{TE}_{i t}$ as an expansion-adjusted output level. The second-stage SFA regression that relies on Huang et al. (2014) for a simple Cobb-Douglas production function is hence: 


$$
\begin{aligned}
\ln \left(Y_{i t}^{\mathrm{adj}}\right) & =\beta_{0}+\beta_{L} \ln L_{i t}+\beta_{K} \ln K_{i t}+\beta_{E} \ln E_{i t}+v_{i t}^{*}-u_{i t}^{*} \\
& =\ln f^{M}(X)+v_{i t}^{*}-u_{i t}^{*} \\
& =\ln Y_{i t}^{*}+v_{i t}^{*}-u_{i t}^{*}
\end{aligned}
$$

where $\ln f^{M}(X)$ denotes the metafrontier production function. That is, the group optimal output level may be still below the metafrontier optimal output level, which fits the concept of technology gap. Equation (9) generates the technology gap ratio DMU $i$ at time $t$ :

$$
\mathrm{TGR}_{i t}=\exp \left(-u_{i t}^{*}\right) .
$$

However, in the TFEE estimation which is for input technical efficiency we instead use the input distance function such as in Eq. (5). In the second stage, we first find the optimal energy input by contracting the actual energy input such that $E_{i t}^{\text {adj }}=E_{i t} \times \mathrm{TFEE}_{i t}$. Our second-stage SFA regression hence becomes:

$$
\begin{aligned}
\ln \left(1 / E_{i t}^{\mathrm{adj}}\right)= & \beta_{0}+\beta_{L} \ln L_{i t}+\beta_{K} \ln K_{i t}+\beta_{Y} \ln Y_{i t}+\frac{1}{2} \beta_{L L} \ln L_{i t}^{2}+\frac{1}{2} \beta_{K K} \ln K_{i t}^{2}+\frac{1}{2} \beta_{Y Y} \ln Y_{i t}^{2} \\
& +\beta_{L K} \ln L_{i t} \ln K_{i t}+\beta_{L Y} \ln L_{i t} \ln Y_{i t}+\beta_{K Y} \ln K_{i t} \ln Y_{i t}+v_{i t}^{*}-u_{i t}^{*} \\
= & \ln f^{M}(X, Y)+v_{i t}^{*}-u_{i t}^{*} \\
= & \ln \left(1 / E_{i t}^{*}\right)+v_{i t}^{*}-u_{i t}^{*} .
\end{aligned}
$$

Equation (12) generates the total-factor energy technology gap ratio for region $i$ at time $t$ as

$$
\mathrm{TGR}_{i t}=\exp \left(-u_{i t}^{*}\right)
$$

and following the time-varying model of Battese and Coelli (1992), $u_{i t}^{*}$ is defined by

$$
u_{i t}^{*}=\eta_{i t} u_{i}^{*}=\{\exp (-\eta(t-T))\} u_{i}^{*} .
$$

Following the new two stages of Huang et al. (2014) by using only SFA, we can obtain

$$
\mathrm{TFEE}_{i t}^{*}=\mathrm{TFEE}_{i t} \times \mathrm{TGR}_{i t},
$$

where $\mathrm{TFEE}_{i t}^{*}$ is the metafrontier TFEE score for region $i$ at time $t$; $\operatorname{TFEE}_{i t}$ is the group TFEE score for region $i$ at time $t$; $\mathrm{TGR}_{i t}$ is the technology gap ratio score for region $i$ at time $t$. All of the $\mathrm{TFEE}_{i t}^{*}, \mathrm{TFEE}_{i t}$, and $\mathrm{TGR}_{i t}$ scores are left censored at 0 and right censored at 1, fitting the usual definition of an efficiency score. Huang et al. (2014) also point out that we can also follow Battese and Coelli (1995) to simultaneously estimate the stochastic frontier and equation of inefficiency (with the environmental variables).

Figure 1 is drawn to illustrate the input-oriented technical efficiencies. There are two inputs, $x_{1}$ and $x_{2}$, and sole output, $y$. Note that the metafrontier envelops each group frontier. Assume DMU A belongs to group 2 and operates at the point A. The point $A^{\prime}$ projected to the group frontier 2 denotes the activity that inefficiency from the management is resolved. Then, the group technical efficiency is defined as $O A^{\prime} / O A$. Similarly $A^{\prime \prime}$ projected to the metafrontier denotes the efficient activity that can be achieved using the best available technology. Then, the TGR is defined as $O A^{\prime \prime} / O A^{\prime}$. Then, the metafrontier 


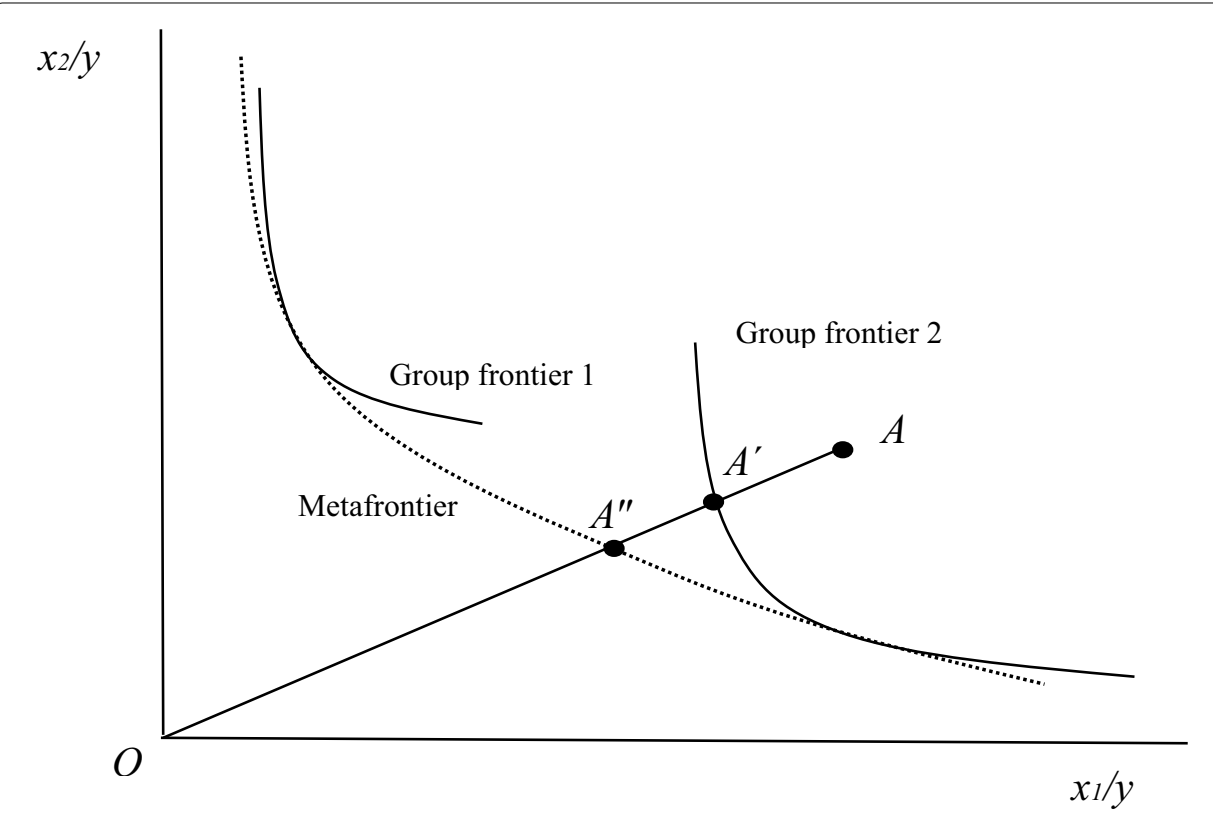

Fig. 1 Metafrontier and group frontiers

technical efficiency is $O A^{\prime \prime} / O A=\left(O A^{\prime} / O A\right) \times\left(O A^{\prime \prime} / O A^{\prime}\right)$. There are many factors affecting the regional energy efficiency (Jaffee et al. 2004; Wei and Liao 2016). For instance, the factors of higher levels of income, value added, technology, education, urbanization, equipment, transportation, residential environment, user characteristics, market operation, etc. can effectively affect the regional energy efficiency. Due to data limitations and degree of freedom requirement for regression, we cannot include all of them in one regression. However, the industrial structure is a most direct factor to affect regional energy efficiency since it will directly affect the value added and energy usage in a region (Casler and Hannon 1989). Moreover, the social and economic conditions will also directly affect the regional energy efficiency (Medina et al. 2016). For example, a higher per capita income enables people to access to energy-saving technology and productivity models, which will improve the regional energy efficiency (Hu and Wang 2006). The government services may help improve the regional energy efficiency by improving the infrastructure (Medina et al. 2016). Moreover, the government policy gives firms incentive to improve their energy efficiency (Johnstone et al. 2017; Yang et al. 2017). Figure 2 depicts the research framework of this paper.

We introduce the following eight environmental variables in the group frontier estimation. They are four industrial shares (energy-intensive manufacturing industry share, non-energy-intensive manufacturing industry share, wholesale and retail trade industry share), and service activities industry share, and three economic and social conditions (share of government services, population density, income per capita), and time. On a relative base, manufacture of ceramic, stone and clay products, manufacture of chemical and allied products, manufacture of primary metal, manufacture of pulp, and paper and paper products are taken as energy-intensive manufacturing industry, while other manufacturing industries are taken as non-energy intensive. 


\begin{tabular}{|c|c|c|c|}
\hline \multicolumn{2}{|c|}{$\begin{array}{l}\text { Industrial structure } \\
\text { Energy-intensive manufacturing } \\
\text { industry share } \\
\text { Non-energy-intensive manufacturing } \\
\text { industry share } \\
\text { Wholesale and retail trade industry } \\
\text { share } \\
\text { Service activities industry share } \\
\text { Social-economic Environments } \\
\text { Government services share } \\
\text { Population density } \\
\text { Income per capita }\end{array}$} & $\begin{array}{l}\text { Technology } \\
\text { gap ratio }\end{array}$ & $\begin{array}{c}\text { Metafrontier } \\
\text { total-factor } \\
\text { energy } \\
\text { efficiency }\end{array}$ \\
\hline
\end{tabular}

\subsection{Data}

Most data sources of the present paper are the same as our previous work (Honma and $\mathrm{Hu}$ 2014a). Data on energy consumption are taken from Agency for Natural Resources and Energy (2013), ${ }^{4}$ whereas data on economic variables are taken from the Cabinet Office (2013a, b). All monetary values are given in 2000 million yen. We classified 47 regions into two groups depending on whether a region has at least a government-designated city, ${ }^{5}$ we call it as a major city for simplicity, which has more than 500 thousand people and can carry out the authorities that are delegated by the prefecture government. Group 1 consists of a region with at least one designated city, which has many functions normally performed by prefectural government. Although Tokyo accurately has not a government-designated city, but the capital with special wards, we deemed that Tokyo also belongs to the group $1 .^{6}$ Group 2 consists of the rest of the regions. As

\footnotetext{
${ }^{4}$ In our dataset, energy consumption of fossil fuel combustion in electricity sector is attributed to each of the industry sectors.

5 The 47 regions can be divided into three or more groups on the basis of other criteria, e.g., industrial structure. However, if so, we encounter difficulties to draw clear lines to separate them. Accordingly, in this study we use the criterion whether a prefecture has at least a government-designated city to objectively determine groups. Further studies may try other possible subgrouping criteria.

${ }^{6}$ Recently, the designated city requirement relaxed from one million to half a million in population. During and after our sample period, 1996-2008, five regions, Saitama, Shizuoka, Niigata, Okayama, and Kumamoto, had designated cities in 2003, 2005, 2007, 2009, and 2012, respectively. We entered these regions into group 1 because these cities functioned as a central city in each regional economy before being designated cities.
} 
Table 1 Characteristics of each group

\begin{tabular}{|c|c|c|c|c|}
\hline Region & Unit & $\begin{array}{l}\text { Group } 1 \\
\text { (metropolitan } \\
\text { area) }\end{array}$ & Group 2 (rural area) & Total \\
\hline Regional GDP based in the year of 2000 & Million yen & $23,209,201$ & $5,104,223$ & $11,267,620$ \\
\hline Labor employment & Person & $2,652,047$ & 691,162 & $1,358,697$ \\
\hline Capital stock based in the year of 2000 & Million yen & $67,173,363$ & $19,988,571$ & $36,051,479$ \\
\hline Energy consumption & TJ & 394,143 & 105,684 & 203,883 \\
\hline $\begin{array}{l}\text { Energy-intensive manufacturing industry } \\
\text { share }\end{array}$ & Proportion & 0.043 & 0.047 & 0.045 \\
\hline $\begin{array}{l}\text { Non-energy-intensive manufacturing industry } \\
\text { share }\end{array}$ & Proportion & 0.163 & 0.169 & 0.167 \\
\hline Wholesale and retail trade share & Proportion & 0.135 & 0.101 & 0.113 \\
\hline Service activities share & Proportion & 0.197 & 0.190 & 0.193 \\
\hline Government services & Proportion & 0.090 & 0.119 & 0.109 \\
\hline Population density & Person $/ \mathrm{km}^{2}$ & 1376 & 253 & 635.36 \\
\hline Income per capita based in the year of 2000 & Million yen & 3108 & 2734 & 2861.26 \\
\hline
\end{tabular}

a result, numbers of regions in two groups are different. Number of Group 1 is 16 and number Group 2 is 31 . We sometimes call the former as the metropolitan areas and the latter as the non-metropolitan or rural areas.

Table 1 presents the characteristics of each group.

\section{Results}

\subsection{ML simultaneous estimates of efficiency and its determinants}

The ML estimates of group TFEE and TGR scores are calculated using the Frontier 4.1 software (Coelli 1996). Table 2 presents the ML simultaneous estimates of efficiency and its determinants. The group TFEE and its determinants are simultaneously estimated using Eqs. (5)-(7) by groups on the basis of the group frontier, and the results are shown in the first and second columns. The TGR is estimated by Eq. (11) on the basis of the metafrontier. Note that a positive (negative) coefficient of each environmental variable means an inefficiency-reducing (-inducing) factor. First of all, the coefficients of the share of energy-intensive manufacturing industry for both groups are positive and statistically significant at $1 \%$ level. The large coefficients imply that larger share of energy-intensive manufacturing industry deteriorates immensely. Non-energy-intensive share has negative coefficients but significant only for group 1. Coefficients of wholesale and retail trade industry share are positive and statistically significant only for group 2, implying that rising the share corresponds to lower efficiency. They are the same signs to our previous study (Honma and $\mathrm{Hu} 2014 \mathrm{a}$ ). The coefficient of service activities industry share is positive for group 1 in contrast to negative for group 2 . This indicates that the more service activities industry is, the more (less) energy inefficient for group 1 (group 2 ) is. The difference of this result might come from a difference of subindustries because of a wide variety of service industry, e.g., a region in group 1 tends to have many large scale hotels but one in group 2 does not so.

The rest of four variables, $\delta_{5}-\delta_{8}$, are newly added to the previous environmental variables in Honma and $\mathrm{Hu}$ (2014a). The coefficient of share of government service is statistically significant and negative sign but statistically significant only for group 2 , implying 
Table 2 ML estimates of efficiency and its determinants

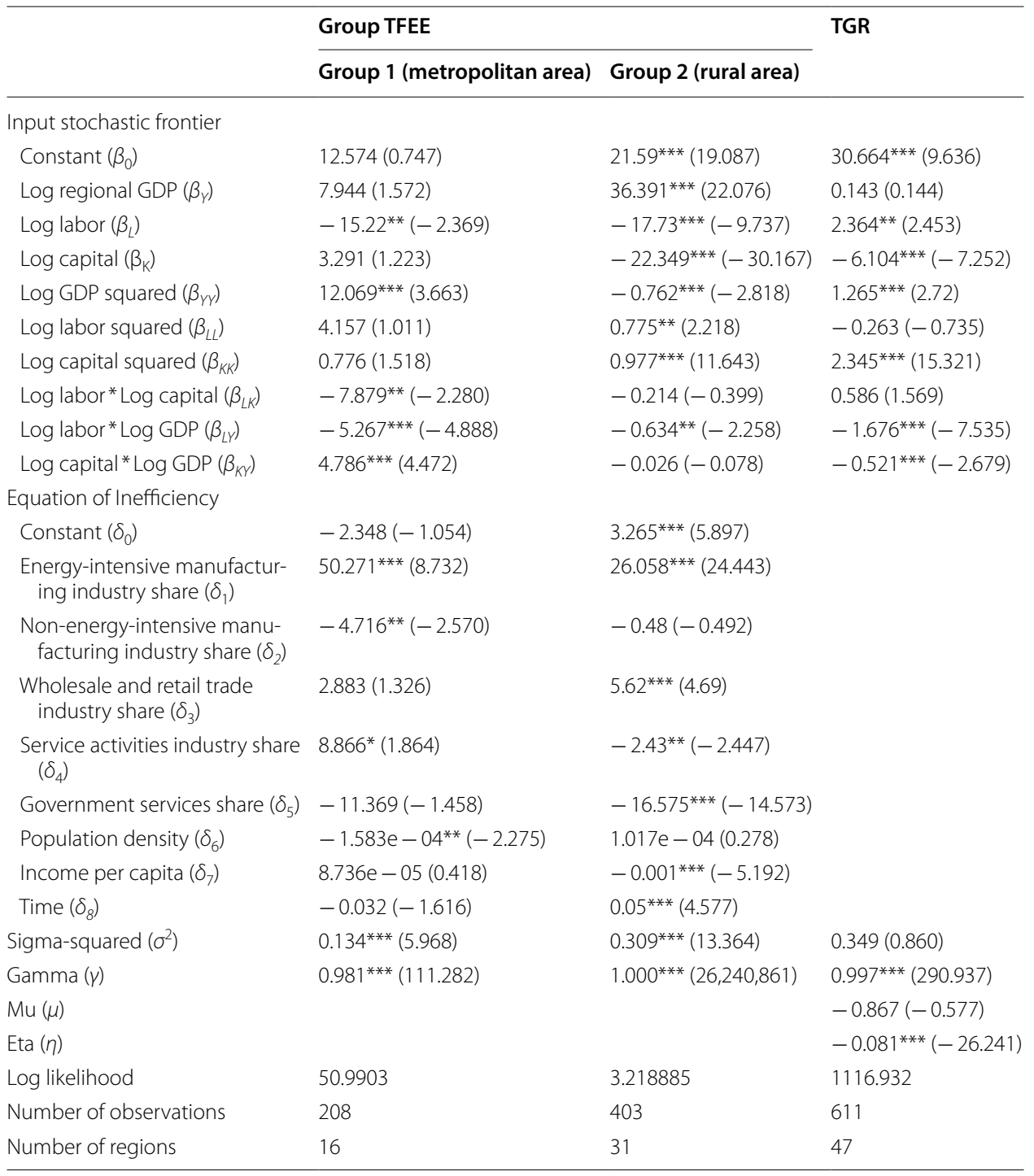

$t$ values are in parentheses

***, ${ }^{* *}$, and $*$ Significant at the 1,5 , and $10 \%$ levels, respectively

that higher government share in a regional economy has a positive effect on energy efficiency. A plausible explanation may come from the fact that government services such as administrative services, police service, and education are mostly non-energy intensive.

The coefficient of population density is statistically significant only in group 1 . The positive sign that implies higher population density induces lower energy efficiency; however, the magnitude of the coefficient of group 1 is considerably small. ${ }^{7}$ The

\footnotetext{
${ }^{7}$ Compact city, which facilitates energy-efficient smarter city, has received considerable attention and has been implemented as an urban policy in several cities, e.g., Aomori, and Toyama, in recent years. However, such urban policy is city level, because our empirical analysis is performed by prefecture level, the impacts of compact city on energy efficiency cannot be observed in the empirical results.
} 
coefficient of income per capita is negative and statistically significant only for group 2, meaning the higher the per capita income, the higher the energy efficient. This is consistent with a fact that the environmental quality is a superior good. The coefficient for Time in group 2 is positive and statistically significant, implying that energy inefficiency tends to increase within the group throughout the sample years. Strengthening energysaving regulation during the sample period may have a negative impact on the energy productivity for group 2, which was amended in 1998, 2002, and 2005.

In the SFA likelihood function, variances of $v$ and $u, \sigma_{v}^{2}$ and $\sigma_{u}^{2}$ are estimated by reparameterized $\sigma^{2}=\sigma_{v}^{2}+\sigma_{u}^{2}$ and $\gamma=\sigma_{u}^{2} / \sigma^{2}$, respectively. Hence, $\gamma$ presents the relative contributions of $u$ to the error components, taking between 0 and 1 . The large values of $\gamma$ for the three models in Table 2 imply that the variance in the error components is almost explained by technical inefficiency. The time inefficiency term, $\eta$, in the TGR column shows that the technology gap expanded as a whole during the sample period. Strengthening energy-saving regulation during the sample period may also have a negative impact on the energy productivity for the metafrontier.

\subsection{TFEE scores}

Table 3 presents the mean group TFEE and TGR scores for the years 1996-2008. For example, the first row reports that the mean group TFEE of Kumamoto is 0.952, implying that Kumamoto could reduce energy consumption up to $95.2 \%$ of the actual energy input using the same other inputs and output and the production technology available in group 1. The second columns present the mean TGRs. The mean TGR of Kumamoto, 0.899 , implies that Kumamoto could reduce energy by another $11.1 \%(=1-0.899)$ using $95.2 \%$ of the actual energy input and the best available technology. In total, Saitama could reduce $14.5 \%(=1-0.855)$ of energy using the unrestricted meta-technology.

The first column reports the mean group TFEE, in which regions are sorted by the group TFEE scores within the same group. For group 1 (metropolitan area), the top three regions with respect to the group TFEE (i.e., Kumamoto, Kyoto, and Saitama) are also efficient for the TGR. The bottom three regions for the group TFEE (i.e., Hiroshima, Chiba, and Okayama) are also inefficient for the TGR, making their metafrontier TFEE scores extraordinarily low which are below 0.3 ; that is, they can save more than $70 \%$ of their energy. The fact that the group TFEE scores for the three regions are much lower than the TGRs suggests that improving operating inefficiency with the existing available technology in Japan is crucial for these regions.

For group 2, in contrast to group 1, a higher group TFEE does not necessarily mean a higher TGR score. The bottom three regions for the group TFEE, Ibaraki, Yamaguchi, and Oita, are ranked not so bad for TGR rankings; however, these regions can cut energy consumption more than $75 \%$ due to their low group TFEE. For group 1 and 2, the mean group TFEE is smaller than the mean TGR. Furthermore, for the TGR there is no region below 0.5; however, for the group TFEE four regions in group 1 and seven regions in group 2 fall below 0.5, respectively. This implies the inefficiency of the metafrontier TFEE is mainly attributed to the operation rather than the technology used in the group. Before examining the TGRs, we would like to investigate whether the technologies of the two groups are heterogeneous. For this purpose, we 
Table 3 Mean TFEEs and TGR by region in Japan (1996-2008)

\begin{tabular}{|c|c|c|c|c|c|c|}
\hline Region & Group TFEE & & TGR & & $\begin{array}{l}\text { Metafrontier } \\
\text { TFEE }\end{array}$ & \\
\hline \multicolumn{7}{|c|}{ Group 1 (metropolitan) } \\
\hline Kumamoto & 0.952 & $(1)$ & 0.899 & $(2)$ & 0.855 & (2) \\
\hline Kyoto & 0.939 & $(2)$ & 0.987 & $(1)$ & 0.927 & (1) \\
\hline Saitama & 0.934 & (3) & 0.874 & (4) & 0.815 & (3) \\
\hline Hokkaido & 0.932 & $(4)$ & 0.540 & $(16)$ & 0.501 & (9) \\
\hline Tokyo & 0.898 & (5) & 0.898 & (3) & 0.806 & (4) \\
\hline Niigata & 0.884 & (6) & 0.632 & (15) & 0.554 & (8) \\
\hline Miyagi & 0.881 & $(7)$ & 0.802 & (5) & 0.705 & (5) \\
\hline Osaka & 0.838 & (8) & 0.726 & $(11)$ & 0.603 & (7) \\
\hline Shizuoka & 0.821 & (9) & 0.765 & (7) & 0.624 & (6) \\
\hline Aichi & 0.738 & $(10)$ & 0.653 & (14) & 0.477 & (11) \\
\hline Fukuoka & 0.629 & $(11)$ & 0.782 & (6) & 0.488 & (10) \\
\hline Hyogo & 0.535 & $(12)$ & 0.675 & (13) & 0.356 & (13) \\
\hline Kanagawa & 0.477 & (13) & 0.763 & (8) & 0.362 & (12) \\
\hline Hiroshima & 0.378 & (14) & 0.748 & (9) & 0.282 & (14) \\
\hline Chiba & 0.208 & (15) & 0.746 & $(10)$ & 0.155 & (15) \\
\hline Okayama & 0.168 & (16) & 0.724 & $(12)$ & 0.120 & (16) \\
\hline Group 1 mean & 0.701 & & 0.763 & & 0.539 & \\
\hline \multicolumn{7}{|l|}{ Group 2 (rural) } \\
\hline Ishikawa & 0.963 & (1) & 0.950 & $(12)$ & 0.915 & (2) \\
\hline Yamagata & 0.960 & (2) & 0.933 & $(16)$ & 0.896 & (5) \\
\hline Shimane & 0.959 & (3) & 0.701 & (30) & 0.673 & (16) \\
\hline Okinawa & 0.957 & (4) & 0.919 & $(18)$ & 0.880 & (6) \\
\hline Nagano & 0.945 & (5) & 0.979 & (4) & 0.925 & (1) \\
\hline Nagasaki & 0.943 & (6) & 0.962 & $(10)$ & 0.907 & (3) \\
\hline Nara & 0.924 & $(7)$ & 0.973 & (6) & 0.899 & (4) \\
\hline Saga & 0.915 & (8) & 0.789 & (28) & 0.725 & (13) \\
\hline Yamanashi & 0.894 & (9) & 0.894 & $(22)$ & 0.799 & (7) \\
\hline Akita & 0.853 & $(10)$ & 0.904 & $(20)$ & 0.772 & (9) \\
\hline Gumma & 0.803 & $(11)$ & 0.975 & (5) & 0.783 & (8) \\
\hline Tochigi & 0.793 & $(12)$ & 0.858 & (24) & 0.680 & (15) \\
\hline Fukushima & 0.786 & (13) & 0.967 & (8) & 0.760 & (10) \\
\hline Iwate & 0.763 & (14) & 0.985 & (3) & 0.751 & (11) \\
\hline Kagoshima & 0.753 & (15) & 0.997 & (1) & 0.751 & (12) \\
\hline Tottori & 0.740 & (16) & 0.731 & (29) & 0.543 & (20) \\
\hline Gifu & 0.729 & $(17)$ & 0.989 & $(2)$ & 0.721 & (14) \\
\hline Fukui & 0.699 & (18) & 0.827 & $(27)$ & 0.581 & (18) \\
\hline Miyazaki & 0.657 & (19) & 0.903 & $(21)$ & 0.592 & (17) \\
\hline Kochi & 0.649 & $(20)$ & 0.648 & (31) & 0.420 & (25) \\
\hline Shiga & 0.644 & $(21)$ & 0.891 & $(23)$ & 0.572 & (19) \\
\hline Tokushima & 0.577 & $(22)$ & 0.842 & $(25)$ & 0.486 & (22) \\
\hline Aomori & 0.521 & (23) & 0.962 & (9) & 0.502 & (21) \\
\hline Toyama & 0.509 & (24) & 0.925 & (17) & 0.472 & (23) \\
\hline Kagawa & 0.458 & $(25)$ & 0.937 & (15) & 0.429 & (24) \\
\hline Ehime & 0.341 & $(26)$ & 0.967 & (7) & 0.330 & (26) \\
\hline Wakayama & 0.332 & $(27)$ & 0.833 & $(26)$ & 0.277 & (27) \\
\hline Mie & 0.249 & (28) & 0.910 & (19) & 0.226 & (29) \\
\hline Ibaraki & 0.248 & (29) & 0.938 & (14) & 0.233 & (28) \\
\hline
\end{tabular}


Table 3 (continued)

\begin{tabular}{|c|c|c|c|c|c|c|}
\hline Region & Group TFEE & & TGR & & $\begin{array}{l}\text { Metafrontier } \\
\text { TFEE }\end{array}$ & \\
\hline Yamaguchi & 0.136 & (30) & 0.953 & $(11)$ & 0.129 & (30) \\
\hline Oita & 0.117 & (31) & 0.943 & (13) & 0.110 & (31) \\
\hline Group 2 mean & 0.671 & & 0.903 & & 0.605 & \\
\hline Total mean & 0.681 & & 0.855 & & 0.582 & \\
\hline
\end{tabular}

investigate the likelihood ratio (LR) test for the null hypothesis that the production frontier is the same for the groups. Denote the maximum likelihood functions of the null and alternative hypothesis as $L_{0}$ and $L_{1}$. While the value of $\log L_{0}$ is 4.848 , the value of $\log L_{1}$ is 54.209 , which is given by the sum of the two log likelihood function values in Table 2 . The $\log$ LR test statistics, $-2\left(\log L_{0}-\log L_{1}\right)=98.723$, clearly rejects the null hypothesis. We can conclude that the technologies in the two groups are heterogeneous. It supports that the metafrontier approach to estimate energy efficiency.

Our central concern of this paper is the technology gap ratio (TGR). The mean TGR for the metropolitan areas (group 1), 0.763 , during the sample period is, counterintuitively, lower than that for the rural areas (group 2), 0.903 . This is not consistent with the previous studies such as Hu and Wang (2006), which show that metropolitan areas are, as a whole, more efficient than non-metropolitan areas in China.

Figure 3a-c presents the histograms of the three TGRs during the years 1996-2008. Group 1 has two peaks, which are located in the range of $0.7-0.75$ and $0.8-0.85$; however, the former peak is lower than the latter (Fig. 3a). This means that group 1 involves many regions which are far from the metafrontier even their within-group inefficiencies are resolved. In contrast to group 1 (metropolitan area), group 2 (rural area) has a left-skewed distribution and has a long tail (Fig. 3b). The above difference in distributions of TGR scores implies that the rural areas, as a whole, are closer to the metafrontier than the metropolitan areas, when within-group inefficiency is resolved.

It should be highly unlikely that there is a large technological gap between the two groups in Japan, as between developed and developing countries. This is because Japan may have more equal access to technology and funding for its rural and urban areas. As Fig. 3a, b shows, however, the TGRs of the metropolitan areas are distributed lower than those of the rural areas. This is an aggregate result from many factors. As Table 2 shows, an increase in the share of energy-intensive manufacturing industry increases the energy inefficiency in both groups. The metropolitan areas still have manufacturing industries and have to improve their energy efficiency, too. The service activities industry share increases the energy inefficiency in group one, while it decreases the energy inefficiency in group 2, implying that the service activities in the metropolitan areas in Japan are not energy efficient and still have much room to improve their energy efficiency. The income per capita has no significant effect in group 1, while it still significantly reduces energy inefficiency in group 2, implying that income per capita is not a main driving force to decrease energy inefficiency in the metropolitan areas in Japan. Instead, energy-saving 

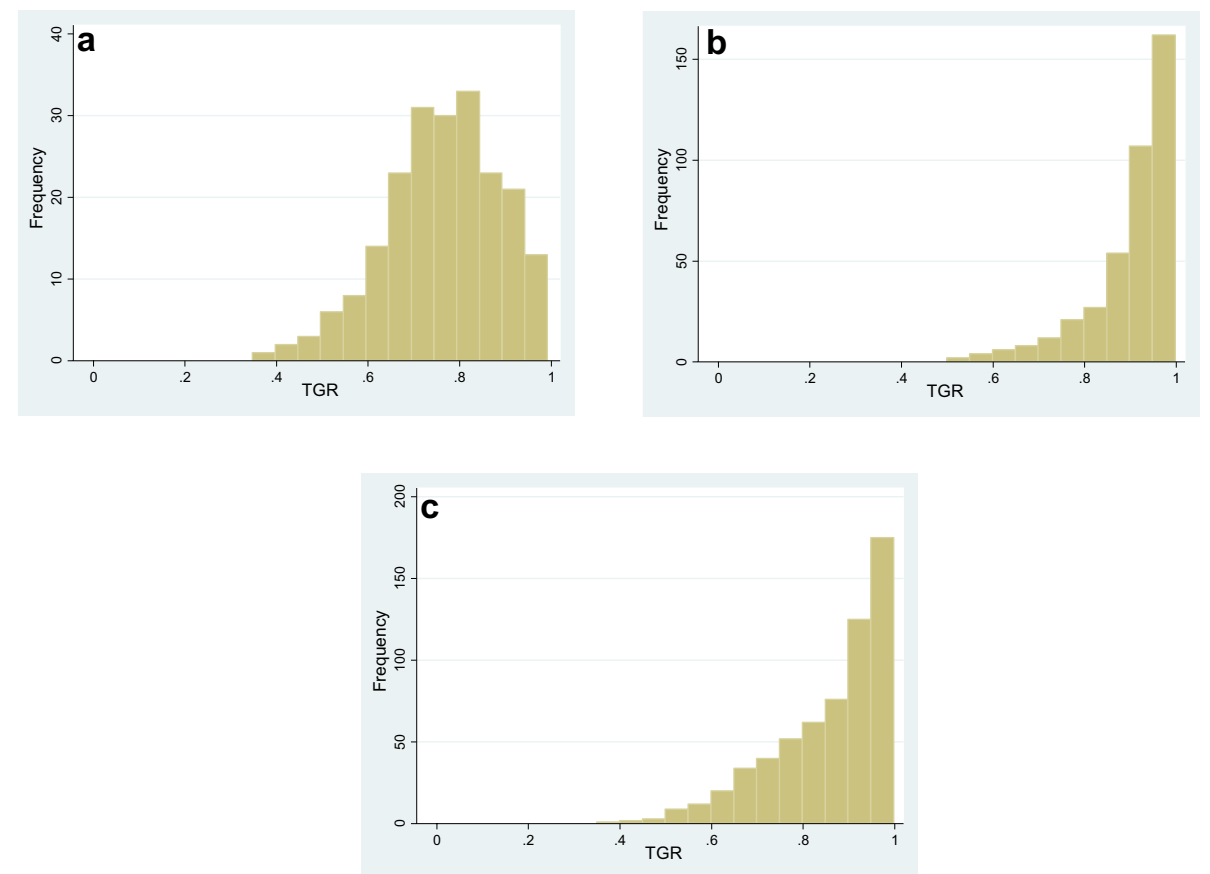

Fig. 3 Histograms of the TGRs. a Group 1 (metropolitan). b Group 2 (rural). c Total

measures and government services are the main driving forces to improve regional energy efficiency in both metropolitan and rural areas in Japan.

\section{Concluding remarks}

This paper measured the metafrontier total-factor energy efficiency (TFEE) of 47 regions in Japan for the period 1996-2008, using metafrontier approach, which allows technological heterogeneity among region groups. ${ }^{8}$ We divided the 47 regions into two groups, group 1 (referred the metropolitan areas) with at least a major (designated) city and group 2 (referred the non-metropolitan/rural areas) without one. The target ratio (TGR) was defined as a ratio between the metafrontier TFEE and the group frontier TFEE. The metafrontier TFEE was evaluated using a set of the minimum energy input which consists of the real energy consumption multiplied by the group frontier TFEE for each region in the whole region. The contribution of the paper is that energy efficiency as an input efficiency in the total-factor framework is evaluated allowing heterogeneous technologies and that a primary source of the inefficiency is identified, using the metafrontier technique in the SFA.

The group TFEE and TGR scores provide policy implications for each region, which depend on both of magnitudes. In the general case, if a region has high rankings for both the group TFEE and TGR, the region could be a good model for inefficient regions in the same group. In the case that both of the group TFEE and TGR in a region are

\footnotetext{
${ }^{8}$ In 2008, Japanese economy was hit by the financial crisis triggered by the collapse of Lehman Brothers. Since this year is at the end of our sample period, we are incompetent to discuss how the crisis impacts on efficiency for Japanese industry. See Fujii et al. (2016) for further analysis on this point.
} 
low, fulfilling the technology gap and then improving the operation are required for the region's economy. For mixed results, the relative scales of the two indices provide policy priority to improve energy conservation. If a region's TGR is lower than its TGR, inefficiency is mainly attributed to state-of-the-art technology. New technology should be introduced in the region. Conversely, if a region's group TFEE is lower than the TGR, then operating efficiency in the region should be improved. Several caveats on the technology gap should be noted, as discussed in the end of Sect. 3. The above implications are denoted to general cases, what technology gap means should be cautiously interpreted in application to specific regions.

The fact that the mean group TFEE is smaller than the mean TGR for both the groups shows that energy inefficiency with respect to the metafrontier comes from primarily operating inefficiency, rather technology gap. The mean metafrontier TFEE of group 1 is smaller than that of group 2. It implies that the metropolitan areas, counterintuitively, are energy inefficient than the rural areas. The mean TGR of the group 1 is also smaller than that of group 2, implying that many regions in group 1 are far from the metafrontier.

Our approach allows to measure energy, or other input, efficiency and its determinants for economies with heterogeneous technologies and to decompose the sources of the inefficiency into production environment and technology gap. Unlike the previous common frontier analysis, policy implications to save the input analyzed can be obtained.

\section{Authors' contributions}

$\mathrm{JH}$ proposed the models, wrote the theoretical part, and co-worked on the policy implications. SH collected the data, did the computational analysis, and wrote the empirical part. Both authors read and approved the final manuscript.

Author details

${ }^{1}$ School of Political Science and Economics, Tokai University, 4-1-1 Kitakaname, Hiratsuka City, Kanagawa 259-1292, Japan. ${ }^{2}$ Institute of Business and Management, National Chiao Tung University, Taipei City 10044, Taiwan.

\section{Acknowledgements}

The authors would like to thank the anonymous reviewers for their valuable comments and suggestions to improve the quality of the paper. The first version of this study was presented at the 5 th Congress of the East Asian Association of Environmental and Resource, held in Taipei, Taiwan, from 5 to 7 August 2015. The first author was supported by JSPS KAKENHI Grant Number 16K03662. The second author was supported by MOST104-2410-H-009-052.

Competing interests

There is no financial or non-financial competing interest in relation to this work.

Availability of data and materials

See Sect. 2.2 for all data sources.

\section{Consent for publication}

Not applicable.

Ethics approval and consent to participate

Not applicable.

Funding

This research is financially supported by JSPS KAKENHI Grant Number 25380346 and Taiwan's Ministry of Science and Technology (MOST104-2410-H-009-052).

\section{Publisher's Note}

Springer Nature remains neutral with regard to jurisdictional claims in published maps and institutional affiliations.

Received: 1 March 2018 Accepted: 17 August 2018

Published online: 23 August 2018 
References

Agency for Natural Resources and Energy. Japan (2013) Energy consumption statistics by prefecture. Tokyo, Japan

Battese GE, Coelli TJ (1992) Frontier production functions, technical efficiency and panel data: with application to paddy farmers in India. J Product Anal 3:153-169

Battese GE, Coelli TJ (1995) A model for technical inefficiency effects in a stochastic frontier production function for panel data. Empir Econ 20:325-332

Battese GE, Rao DP (2002) Technology gap, efficiency, and a stochastic metafrontier function. Int J Bus Econ 1(2):87-93

Battese GE, Rao DP, O'Donnell CJ (2004) A metafrontier production function for estimation of technical efficiencies and technology gaps for firms operating under different technologies. J Prod Anal 21(1):91-103

Cabinet Office, Government of Japan (2013a) Economic and fiscal model by prefecture, Cabinet Office, Government of Japan, Tokyo

Cabinet Office, Government of Japan (2013b) Annual report on prefectural accounts, Cabinet Office, Government of Japan, Tokyo

Casler S, Hannon B (1989) Readjustment potentials in industrial energy efficiency and structure. J Environ Econ Manag 17(1):93-108

Coelli TJ (1996) A guide to FRONTIER version 4.1: a computer program for stochastic frontier production and cost function estimation. In: CEPA working paper 96/7, University of New England, Armidale, NSW, Australia

Fujii H, Assaf AG, Managi S, Matousek R (2016) Did the financial crisis affect environmental efficiency? Evidence from the Japanese manufacturing sector. Environ Econ Policy Stud 18(2):159-168

Hayami Y, Ruttan VW (1970) Agricultural productivity differences among countries. Am Econ Rev 60(5):895-911

Hayami Y, Ruttan VW (1971) Agricultural development: an international perspective. John Hopkins University Press, Baltimore

Honma S, Hu JL (2008) Total-factor energy efficiency of regions in Japan. Energy Policy 36:821-833

Honma S, Hu JL (2013) Total-factor energy efficiency for sectors in Japan. Energy Sources Part B 8(2):130-136

Honma S, Hu JL (2014a) A panel data parametric frontier technique for measuring total-factor energy efficiency: an application to Japanese. Energy 78:732-739

Honma S, Hu JL (2014b) Industry-level total-factor energy efficiency in developed countries. Appl Energy 119:37-78

Hu JL, Honma S (2014) A comparative study of energy efficiency of OECD countries: an application of the stochastic frontier analysis. Energy Procedia 61:2280-2283

Hu JL, Kao CH (2007) Efficient energy-saving targets for APEC economies. Energy Policy 35:373-382

Hu JL, Wang SC (2006) Total-factor energy efficiency of regions in China. Energy Policy 34:3206-3217

Hu JL, Lio MC, Kao CH, Lin YL (2012) Total-factor energy efficiency for regions in Taiwan. Energy Sources Part B 7(3):292-300

Huang CJ, Huang TH, Liu NH (2014) A new approach to estimating the metafrontier production function based on a stochastic frontier framework. J Prod Anal 42:241-254

Jaffee AB, Newell RG, Stavins RN (2004) Economics of energy efficiency. In: Cleveland C (ed) Encyclopedia of energy. Elsevier, Amsterdam, pp 79-90

Johnstone N, Managi S, Rodríguez MC, Haščič I, Fujii H, Souchier M (2017) Environmental policy design, innovation and efficiency gains in electricity generation. Energy Econ 63:106-115

Kumar S, Fujii H, Managi S (2015) Substitute or complement? Assessing renewable and nonrenewable energy in OECD countries. Appl Econ 47(14):1438-1459

Medina A, Cámara Á, Monrobel JR (2016) Measuring the socioeconomic and environmental effects of energy efficiency investments for a more sustainable Spanish economy. Sustainability 8:1039

O'Donnell CJ, Rao DP, Battese GE (2008) Metafrontier frameworks for the study of firm-level efficiencies and technology ratios. Empir Econ 34(2):231-255

Tamaki T, Shin KJ, Nakamura H, Fujii H, Managi S (2018) Shadow prices and production inefficiency of mineral resources. Econ Anal Policy 57:111-121

Wei Y, Liao H (2016) Energy economics: energy efficiency in China. Springer, New York

Yang Q, Kaneko S, Fujii H, Yoshida Y (2017) Do exogenous shocks better leverage the benefits of technological change in the staged elimination of differential environmental regulations? Evidence from China's cement industry before and after the 2008 Great Sichuan Earthquake. J Clean Prod 164:1167-1179

Zhou P, Ang BW, Zhou DQ (2012) Measuring economy-wide energy efficiency performance: a parametric frontier approach. Appl Energy 90:196-200

\section{Submit your manuscript to a SpringerOpen ${ }^{\circ}$ journal and benefit from:}

- Convenient online submission

- Rigorous peer review

- Open access: articles freely available online

- High visibility within the field

Retaining the copyright to your article

Submit your next manuscript at $\gg$ springeropen.com 